\title{
A INTERNET COMO AMBIENTE PROPÍCIO PARA O SURGIMENTO DE GÊNEROS HÍBRIDOS: EM FOCO AS NOTÍCIAS HUMORÍSTICAS
}

\author{
KARINE SILVEIRA ${ }^{1}$ \\ Pontifícia Universidade Católica de Minas Gerais \\ Av. Dom José Gaspar, 500 - 30535901 - Belo Horizonte - MG - Brasil \\ karineletras@bol.com.br
}

\begin{abstract}
Resumo. O objetivo deste artigo é verificar como as notícias humorísticas, textos frutos das possibilidades de textualização oferecidas pela Internet, constituem-se como gênero discursivo. Além disso, buscamos compreender a produção do humor nesses textos, já que eles são publicados por sites que parodiam portais de notícias, a saber: Sensacionalista, G17 e O Bairrista. O referencial teórico adotado para fundamentar o estudo da noção de gênero discursivo é o da Análise do Discurso Crítica, de Norman Fairclough (2001, 2003) e a análise da produção de humor ocorreu sob o viés dos estudos semânticos de humor de Raskin (1985) e Attardo (2001). Os resultados obtidos após a análise das notícias humorísticas revelam a emergência de um novo e híbrido gênero para o campo humorístico.
\end{abstract}

Palavras-chave: internet; notícias humorísticas; gênero discursivo; humor.

\begin{abstract}
The main purpose of this article is to verify how humoristic news, texts that are fruits of the possibilities of textualization offered by the Internet, constitute as discursive genre. In addition, they look for a production of humor in the texts, which are already published by the sites they call it news, they are: Sensationalista, G17 and O Bairrista. The theoretical framework adopted to support the study of the discursive genre is Critical Discourse Analysis, proposed by Norman Fairclough $(2001,2003)$ and an analysis of humor production on the semantic studies of humor by Raskin (1985) and Attardo (2001). The results obtained after the analysis of the humorous news revealed the emergence of a new and hybrid humorous genre.
\end{abstract}

Keywords: internet; humorous news; discursive genre; humor.

\footnotetext{
${ }^{1}$ Doutora em Letras e Linguística pela PUC-Minas. Docente no Instituto Federal de Educação, Ciência e Tecnologia do Espírito Santo, Campus Venda Nova do Imigrante.
} 


\section{CONSIDERAÇÕES INICIAIS}

Os textos que intencionalmente se assemelham a notícias, mas que pertencem ao campo do humor, têm despertado o nosso interesse desde a conclusão do projeto de pesquisa de intitulado "Desnotícias sobre o Acre: A construção do humor e de identidades sociais", em 2013. Foram estudadas, nessa ocasião, somente as desnotícias publicadas no site Desciclopédia, mais tarde percebemos que vários outros sites se passavam por portais de notícias, mas na verdade eram sites humorísticos. Vejamos, portanto, um exemplo de um desses textos, que os nomeamos como notícias humorísticas.

\section{(1) Novo Papa faz oração para pedir a vitória da Argentina na Copa do Mundo no Brasil}

A primeira oração do Papa, argentino, será para pedir a vitória da Argentina na Copa do Mundo de 2014, no Brasil. Se depender de uma ajuda divina, através de orações, a Argentina passa a ser a favorita ao título de campeã do mundo em 2014.

Os brasileiros estão tristes. Pelé e Ronaldo não quiseram falar com a imprensa após a escolha do vaticano. A CBF estuda uma forma para realizar um convenio com a Igreja Universal, para orar pelo Brasil na Copa do Mundo.

A derrota do Brasil para a Argentina na escolha do Papa repercutiu no futebol e no mundo.

O exemplo acima foi publicado pelo site G17. O portal, que simula um site jornalístico, apresenta-se da seguinte maneira: "G17 é site de humor. As publicações do site são piadas produzidas para fins de entretenimento". Publicam, portanto, textos que simulam o gênero notícia, mas que pertencem ao campo do humor. O exemplo (1) é baseado nas notícias sobre a mensagem deixada, pelo Papa Francisco, na ocasião da Copa do Mundo de 2014 aos amantes do futebol. Uma dessas notícias foi "Papa manda mensagem aos brasileiros para a Copa e pede solidariedade e paz", publicada pelo site do jornal O Globo em 11 de junho de 2014. Com isso, percebemos a intertextualidade presente no texto (1) e a desconstrução do fato ocorrido, retextualizando-o para o contexto cômico. Notamos ainda a presença do humor no trecho "A $\mathrm{CBF}$ estuda uma forma para realizar um convênio com a Igreja Universal, para orar pelo Brasil na Copa do Mundo", por ser algo inesperado, que surpreende e que não condiz com a realidade.

Esse tipo de manifestação textual, fruto de práticas sociais proporcionadas pelo mundo digital e virtual, resultou no interesse de se investigar questões relacionadas ao gênero de discurso a que pertencem esses textos e à construção do humor, já que eles são identificados como humorísticos pelos sites que os divulga, como é o caso do G17 que publicou o texto (1). Isso posto, pretendemos responder às seguintes questões no estudo aqui desenvolvido:

a) As notícias humorísticas publicadas em três diferentes sites de humor constituem um gênero discursivo? Se sim, como?

b) Como ocorre a produção de efeito humorístico nas notícias humorísticas? 
A escolha dos sites, a saber: Sensacionalista, G17 e O Bairrista, ocorreu com base no número de seguidores que eles possuem na rede social Facebook; número esse bastante significativo. O Sensacionalista conta com mais de três milhões de seguidores; O Bairrista com 400 mil e o G17 possui mais de 200 mil seguidores $^{2}$. Tal escolha justifica-se ainda, pois o Facebook tem sido utilizado por mais de dois bilhões de usuários. Partindo do pressuposto de que a Internet é um ambiente propício para o surgimento de gêneros, podemos, portanto, acreditar que o compartilhamento desses textos, por meio do perfil dos referidos sites no Facebook, é uma forma de fazer com que vários usuários tenham contato com as notícias humorísticas.

É necessário ainda ressaltar que a temática escolhida foi a copa do Mundo de 2014 por ter sido um grande evento realizado no Brasil, o qual vivia um momento de protestos contra a sua realização, já que, segundo muitas pessoas, os investimentos em tal evento poderiam ter sido feitos em áreas carentes como educação, saúde, segurança e infraestrutura. Segundo Possenti (2010, p. 13), “[...] só há piadas sobre assuntos sérios desde que se tornem populares e controversos [...]"; e a Copa, aqui realizada, já era um assunto sério, mas se tornou além de sério, muito controverso.

Além disso, outro fato justifica a nossa motivação em investigar o corpus sob análise: poucos ainda são os trabalhos que buscam compreender a questão do gênero a que pertencem as notícias e a construção do humor nelas. Constatamos isso por meio de um levantamento no Google Acadêmico e no Portal da Capes sobre trabalhos (dissertações, teses, artigos científicos, entre outros) que abordassem nossa proposta de estudo e verificamos que isso não está muito presente ainda no meio acadêmico. Isso nos incitou ainda mais a analisar os textos, chamados de notícias pelos sites que os veiculam, que estivessem relacionadas ao tema "Copa do Mundo de 2014", publicados em portais humorísticos que parodiassem sites de jornalismo.

Isso posto, consideramos importante estudar as notícias humorísticas também, pois elas refletem uma nova organização das práticas sociais de uso da língua. Segundo Silveira (2013), devemos ressaltar a importância das tecnologias da comunicação na produção de novos gêneros, pois:

[...] se não fossem as facilidades propiciadas pela Internet, talvez elas ${ }^{3}$ não existissem, pois uma vez que o acesso a muitas notícias sobre um mesmo fato se tornou simples e rápido, a recontextualização delas em um texto humorístico e parodístico também foi facilitado". (SILVEIRA, 2013, p. 57)

Com o advento da internet, muitas modificações de suporte ocorreram e, por isso, novos gêneros surgiram. Sobre a importância da internet no surgimento de novos gêneros, temos também a reflexão de Freitas, Finelli e Maciel (2014, p. 125).

A internet é uma mídia que utiliza sobremaneira a escrita. [...] Dessa forma, assim como é significativo o papel da linguagem nessa nova tecnologia, esta também provocou efeitos sobre a linguagem. Um

\footnotetext{
${ }^{2}$ Dados atualizados em 13 de fevereiro de 2020.

3 SILVEIRA (2013), ao dizer "elas", faz referência ao seu corpus de pesquisa, as desnotícias, notícias publicadas no site da Desciclopédia.
} 
desses efeitos, que tem sido bastante discutido, é a emergência de novos gêneros textuais".

Para fundamentar o estudo aqui proposto, o referencial teórico adotado advém de duas áreas do conhecimento, tendo em vista que consideramos a noção de gênero do discurso sob o viés da Análise Crítica do Discurso (ADC), especialmente a partir de Fairclough (2001), e a produção do humor à luz dos estudos semânticos de textos humorísticos de Raskin (1985) e Attardo (2001).

Para tornar clara a exposição dos dados, achamos fundamental, em um primeiro momento, tecer algumas considerações sobre a noção de gênero discursivo para a ADC, para, em seguida, expormos a nossa análise do corpus e justificarmos que as notícias constituem um novo e híbrido gênero. Depois, apresentaremos o quadro teórico acerca dos estudos do humor e analisaremos como ocorre a produção de efeito humorístico nos textos sob análise. Em resumo, nosso intuito é verificar como o discurso das notícias humorísticas se organiza para constituir um gênero híbrido e para produzir humor.

\section{A NOÇÃO DE GÊNERO PELO VIÉS DA ADC: EM FOCO A NOTÍCIA}

O estudo dos gêneros discursivos não está entre as principais preocupações da $\mathrm{ADC}$, vertente teórico metodológica cujo principal idealizador e ainda pesquisador é Norman Fairclough, linguista norte-americano da Universidade de Lancaster. No entanto, o conceito de gênero faz-se bastante presente, ao passo que tal abordagem se relaciona com outros tópicos da análise textual que tal vertente realiza.

As obras nas quais encontramos uma abordagem significativa do conceito de gênero foram: Language and Power (1989); Discurso e mudança social (2001 ${ }^{4}$ ); Critical Discourse Analysis: the critical study of language (1995); Discourse in late modernity: rethinking Critical Discourse Analysis (1999, que foi publicado em co-autoria com Lilie Chouliaraki); Analysing Discourse: textual analysis for social research (2003) e Critical discourse analysis in transdisciplinary research (2005). A leitura desse referencial teórico permitiu-nos a elaboração de um esquema, disposto na página seguinte, sobre a evolução do conceito de gênero discursivo na ADC proposta pelo autor em questão.

É em Discurso e Mudança Social (1992/2001), o mais referenciado pelos pesquisadores brasileiros, que Fairclough compreende que a mudança no sistema de gêneros influência e corrobora efeitos nas configurações de outros elementos, ou seja, há relação nas mudanças nas práticas sociais e nos sistemas de gêneros. De acordo com isso, percebemos que as práticas sociais do mundo virtual suscitaram mudanças na maneira de interagir das pessoas e, por isso, novos gêneros surgiram e surgem. $\mathrm{O}$ autor da obra em questão agrega uma visão mais elaborada do conceito de gênero, o qual passa a ser definido como:

[...] um conjunto de convenções relativamente estável que é associado com e parcialmente representa, um tipo de atividade socialmente aprovado, como a conversa informal, comprar produtos em uma loja, uma entrevista de emprego, um documentário de televisão, um poema

\footnotetext{
${ }^{4}$ A versão de 2001 é a versão traduzida, pela UNB, para a língua portuguesa. Originalmente, o livro foi publicado em 1992.
} 
ou um artigo científico. Um gênero implica não somente um tipo particular de texto, mas também processos particulares de produção, distribuição e consumo de textos. Por exemplo, os artigos de jornal e os poemas não são apenas tipos de textos tipicamente bem diferentes, mas eles também são produzidos de formas bem diferentes (por exemplo, um é um produto coletivo, outro e um produto individual); têm distribuição bastante diferente e são consumidos bem diferentemente os últimos incluindo protocolos muito diferentes para sua leitura e interpretação. (FAIRCLOUGH, 2001, p. 161-162)

\section{Esquema 1: Evolução do conceito de gênero discursivo nas obras de Norman Fairclough (elaborado pela autora)}

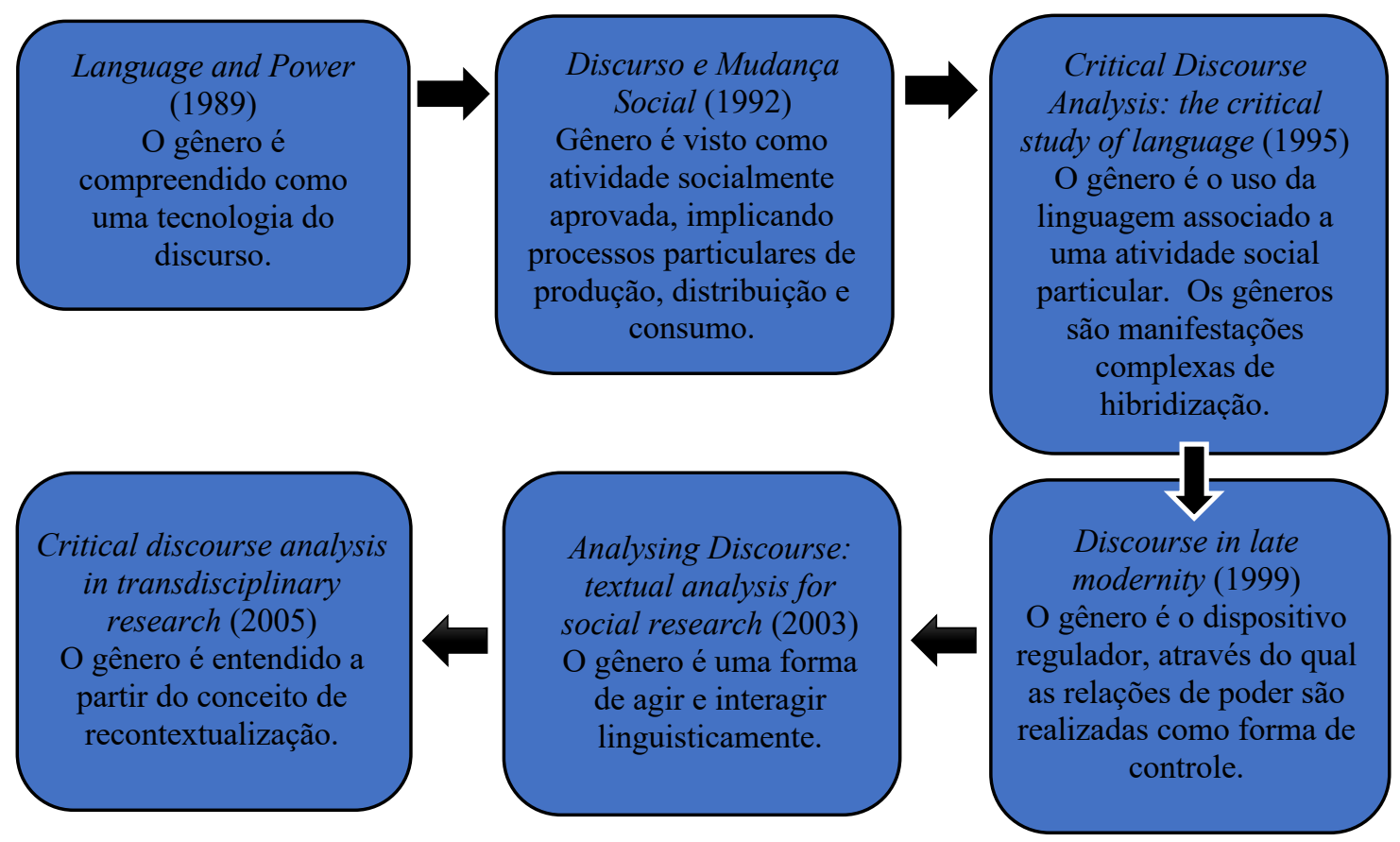

Todavia, consideramos que a principal publicação de Fairclough para os estudos e análises sobre o conceito de gênero discursivo tem sido a de 2003: Analysing Discourse: textual analysis for social research. Este livro elucida muitos conceitos-chave fundamentais para a análise dos gêneros, a saber: estrutura genérica, recontextualização, hibridização de gêneros.

A estrutura genérica configura-se como a estrutura geral ou a organização de um texto, a depender do gênero principal sobre o qual o texto se delimita. Alguns gêneros têm sua estrutura genérica mais bem definida que outros, já que os gêneros não são elementos rígidos e sim flexíveis.

Recontextualização, conceito proposto pelo sociólogo Bernstein em 1990, retomado em Chouliaraki e Fairclough (1999), é entendida como o movimento de incorporar discursos ou gêneros de uma prática social a outra prática social dentro de uma mesma rede de práticas sociais, o que acarreta além da recontextualização a questão da hibridização. Segundo Fairclough (2012, p. 322), “[...] a recontextualização requer transformação”. 
A hibridização de gêneros em Fairclough (2003) é vista como algo complexo, pois um texto não é constituído por um único gênero simplesmente, sendo este um aspecto da interdiscursividade dos textos. Segundo o autor, "[...] os textos frequentemente misturam ou hibridizam diferentes gêneros (exemplo é o bate-papo na televisão que é uma mistura de conversação, entrevista e entretenimento)" (FAIRCLOUGH, 2003, p. 216; tradução nossa). Gênero, na obra em questão, é definido como "[...] uma forma de agir e interagir linguisticamente - por exemplo, entrevista, aula, reportagem são todos gêneros". (FAIRCLOUGH, 2003, p. 17; tradução nossa).

Essa breve exposição acerca do gênero discursivo para Fairclough permitiu-nos verificar como um conceito se desenvolve ao longo dos anos no seio de uma perspectiva teóricometodológica e nos estudos de seu principal pesquisador. Os textos aqui abordados se destacaram não só por introduzirem a noção de gênero discursivo na $\mathrm{ADC}$, bem como por proporem categorias analíticas e conceitos-chave.

No que diz respeito, especificamente, ao gênero notícia, segundo os estudos de Fairclough (1995, 2003), temos a seguinte estrutura: o título, o resumo da notícia (ou lead), os parágrafos satélites (ou parágrafos com detalhes do fato noticiado) e, por fim, o parágrafo de conclusão" (FAIRCLOUGH, 2003, p. 52; tradução nossa). De uma maneira geral, a compreensão da estrutura genérica é importante, pois é uma das características mais evidentes para diferenciar os gêneros. Observe como a estrutura genérica da notícia se manifesta no exemplo abaixo publicado pelo site Sensacionalista:

\section{(2) Dilma revela: Mick Jagger é o responsável pelos gastos da Copa}

Durante uma solenidade realizada nesta terça-feira em Brasília, a presidente Dilma Rousseff revelou tristeza pelas críticas que vem sofrendo por causa dos gastos muito além dos previstos com a Copa do Mundo e afirmou que o grande responsável pela perda do controle foi o vocalista da banda Rolling Stones, Mick Jagger.

"Mick foi o primeiro a ligar para o presidente Lula, 7 anos atrás, para dar os parabéns pela conquista da realização da Copa pelo Brasil. Nesta ligação ele afirmou a Lula que não tinha dúvidas de que a Copa iria resultar em um grande legado para o país e que tinha certeza de que o Brasil realizaria as obras necessárias dentro do prazo e com o mínimo de verba pública. Foi isso. Foi ele!", desabafou Dilma.

Mick Jagger ganhou fama de pé-frio na última Copa, na África do Sul, ao errar todos os palpites dos jogos. Além disso, viu sua fama ganhar proporções mundiais ao afirmar que o Botafogo seria o campeão da Taça Libertadores da América de 2014.

O título faz uso dos verbos no presente para expor os fatos além de fazer menção a duas grandes personalidades, a ex-presidente Dilma e o cantor Mick Jagger, na tentativa de atrair a atenção e interesse do leitor em ler a notícia. No primeiro parágrafo, ou lead, temos o resumo do fato por meio das respostas às perguntas: o quê? Responsabilidade pelos gastos excessivos na Copa. Quem? Mick Jagger. Quando? Nesta terça-feira. Onde? Brasília. Os outros dois parágrafos, ou parágrafos satélites e de conclusão, fornecem um 
maior detalhamento do fato, com causas e consequências. Além disso, há a presença de discurso direto para dar credibilidade ao texto; algo frequente nas notícias.

Todavia, estudar o gênero focalizando somente sua estrutura não faz mais sentido, pois isso o engessa. Para tanto, a ADC concebe o gênero como interação, linguagem em uso. Por isso, ao nos depararmos com um texto, muitas vezes, conseguimos reconhecer o gênero a que ele pertence por causa de nosso conhecimento internalizado da organização genérica, mas somente a leitura e análise do conteúdo permitirá verificar se a hipótese se concretiza, pois alguns textos têm o propósito de enganar, como é o caso dos textos humorísticos aqui analisados.

Além disso, a própria hibridização genérica pode confundir o leitor e o expor a um gênero novo. Como vimos no exemplo (2), que há a simulação da estrutura genérica da notícia, mas a leitura faz com que o leitor perceba que o fato relatado não condiz com a realidade, trazendo elementos surpresas, como o próprio título, e isso revela um texto pertencente ao campo do humor.

Nesse sentido, elencamos alguns tópicos importantes sobre as reflexões de Fairclough (2003) sobre o gênero notícia, a fim de expor que as notícias humorísticas simulam a prática social do jornalismo, a saber:

1. As notícias são constituídas de histórias, de narrativas.

2. O relato dos fatos é ordenado segundo uma intenção do jornal.

3. As notícias são uma forma de regulação social, de controle dos eventos, principalmente se as enxergarmos como aparato de governança.

4. Ao se produzir uma notícia, certos acontecimentos são incluídos enquanto outros são excluídos (segundo a ideologia do jornal ou do jornalista a qual a notícia se veicula).

5. A produção de notícias é um processo árduo de interpretação e construção e não simplesmente um relato dos fatos.

Com base no exposto neste tópico, apresentamos a nossa proposta de reflexão crítica para a análise, no que diz respeito aos textos publicados pelos sites Sensacionalista, G17 e o Bairrista, constituído dos seguintes questionamentos: (1) A que prática(s) social (sociais) os textos sob análise estão associados? (2) Qual o propósito comunicativo das notícias humorísticas? (3) Qual o contexto de produção, distribuição e consumo? (4) Qual a estrutura genérica comum a estes textos? (5) Há a possibilidade de o texto analisado constituir um gênero híbrido proveniente das mudanças nas interações e nos meios de comunicação? Se sim, por quê?

\section{ANÁLISE DO CORPUS: O GÊNERO EM QUESTÃO}

Iniciemos refletindo sobre o trecho da notícia humorística abaixo. O excerto, que se refere ao primeiro parágrafo do texto, "Saci Pererê vai dar o pontapé inicial da Copa no Brasill", publicado pelo site Sensacionalista, permite-nos verificar que ele está vinculado à prática social do jornalismo. Isso justifica-se, pois, primeiramente, é veiculado por um meio que se apresenta como portal de jornalismo e, em segundo lugar, pois relata um evento que aconteceu no período da Copa, a saber: um jovem paraplégico foi o autor do pontapé 
inicial para os jogos do mundial. Todavia, é evidente que o fato foi manipulado, foi desconstruído, pois o jovem paraplégico foi representado pela figura folclórica do Saci Pererê e que este, surpreendentemente, não usaria o seu cachimbo.

(3) ARRAIAL DOS TUCANOS - A Copa do Mundo do Brasil vai
começar de uma forma inusitada. Graças aos esforços da bancada
nacionalista, Saci Pererê vai dar o pontapé que abrirá os jogos. O Saci,
porém, será atualizado para não provocar reações contrárias
politicamente corretas. "Ele não usará cachimbo", explicou um
funcionário da Fifa.

A análise do trecho responde ao nosso primeiro questionamento: a que prática(s) social (sociais) os textos sob análise estão associados? Associam-se não só a prática social do jornalismo, mas também a prática social humorística.

No que diz respeito ao propósito comunicativo, com base nos exemplos já expostos, afirmamos que eles não poderiam ser considerados como notícias, pois notícias visam a informar fatos comprováveis e não é isso que ocorre nos textos sob análise. Logo, o propósito comunicativo das notícias humorísticas é de entretenimento e de crítica social. Além disso, como as notícias humorísticas simulam a prática social do jornalismo e tem como ponto de referência a estrutura genérica da notícia, pois não se prendem tanto à rigidez do gênero, ou seja, são flexíveis a mudanças, o leitor reconhece que lhe é apresentada uma notícia pelo modo de configuração do texto no site, mas ao ler e ativar seus conhecimentos sobre o que é uma notícia, sobre o conteúdo veiculado, sobre o estilo, ele percebe que tal texto é de cunho humorístico, logo elas visam a enganar o leitor que é menos informado sobre os acontecimentos que o rodeia e/ou naquele leitor que não consegue reconhecer os gatilhos humorísticos, as incongruências que o texto apresenta.

No que diz respeito à produção, ao consumo e distribuição verificamos que o contexto de produção é o da Copa do Mundo de 2014 no Brasil, pois foi essa a temática que instigou a escrita de tantas notícias humorísticas. Com relação ao consumo, esse ocorreu por meio do acesso aos sites responsáveis pelas publicações dos textos e por meio da página de cada um desses sites na rede social Facebook. O interesse nos textos publicados no Facebook, justifica-se como uma forma de verificar o consumo e, de certa maneira, a distribuição (se pensarmos no ato do compartilhamento), ou seja, o alcance que as notícias humorísticas tiveram na Internet para além de seus sites de origem. Em relação à distribuição, o Sensacionalista possibilita que seus textos sejam compartilhados do site para as redes sociais Facebook, Google+ e Pinterest. O G17 oferece o compartilhamento via Whatsapp, Twitter e Google+. Já O Bairrista permite somente que seus textos sejam compartilhados pelo Twitter. Destacamos que a distribuição desses textos ocorreu, primeiramente, via site que os publica, e podemos ressaltar que por meio de alguns deles é possível compartilhar os textos, ferramenta comum às publicações, via Facebook. O ato de compartilhar algo indica que o internauta leitor deseja que mais pessoas tenham acesso ao material lido por ele, isso representa, para nós, que o texto foi consumido e que fora distribuído. $\mathrm{O}$ ato de comentar indica o consumo, uma vez que há a necessidade de se ler a notícia para se ter o que falar sobre ela. Por fim, o ato de curtir tende a sinalizar a aprovação do leitor no que diz respeito ao material lido. 
Acerca da estrutura genérica, observemos o texto abaixo que foi publicado pelo site $\mathrm{O}$ Bairrista.

(4) Quinta, 20 de Outubro de 2011
RS desiste de sediar Copa de 2014 junto com o Brazil
"Faremos a nossa própria Copa do Mundo" disse Presidente Tarso.
PORTO ALEGRE, C.F - Após a confirmação na tarde desta quinta-
feira em Zurique de que Porto Alegre está definitivamente fora da Copa
das Confederações e muito perto de perder sua vaga na Copa de 2014,
Tarso Genro, Presidente da República Rio-Grandense, declarou que
nem queria mais mesmo ser sede.
- O Rio Grande do Sul hoje é a sexta economia do mundo, atrás
somente da China, Índia, EUA, Japão e Brazil. Temos totais condições
de sediar a nossa própria Copa - afirmou Tarso.
De acordo com o Presidente, não ser país sede junto com outro país dará
maior visibilidade para o RS:
- Nós teremos total autonomia nas escolhas da nossa Copa. Por
exemplo, a bola poderá se chamar "farroupilha". Outra medida que já
posso anunciar é a do Estádio Boca do Lobo em Pelotas como sede de
uma das semi-finais da Copa - declarou o Presidente.

Tal qual o exemplo (2), a notícia humorística acima baseia-se na estrutura genética da notícia e possui ainda mais detalhes que a aproximam do gênero jornalístico, são eles: o destaque do dia da semana e da data do mês, ambos localizados acima do título, dado este não presente nos textos do site Sensacionalista e G17; além do título, da linha fina, do lead com a localização destacada em caixa alta, dos parágrafos satélites e da presença do discurso direto. Isso nos permite afirmar que a base para produção desses textos é a estrutura genérica da notícia. No entanto, muitas vezes o texto é carregado de avaliações que visam a persuadir o leitor, aproximando esses textos do gênero artigo de opinião. Além disso, como será visto na próxima seção, a presença de recursos humorísticos o aproxima das narrativas das piadas, ou seja, reforçando a classificação do corpus como híbrido e reiterando o teor do humor.

A partir das reflexões realizadas, consideramos que as notícias humorísticas são um novo e híbrido gênero. Novo no que diz respeito ao meio em que são veiculadas: a Internet, e híbrido em relação ao campo a que pertencem: o do humor e ao que simulam: o jornalístico.

\section{A PRODUÇÃO DE SENTIDO HUMORÍSTICO: EM FOCO O ENREDO HUMORÍSTICO}

No tópico anterior, verificamos que o texto das notícias humorísticas constitui um novo e híbrido gênero, mas ainda não fora discutido como o humor é produzido para que possamos justificar o efeito humorístico do gênero. Por isso, nesta seção, dedicamo-nos a compreender o enredo, pois acreditamos ser ele o responsável pela produção de humor em nosso corpus. 
A terminologia "enredo humorístico" utilizada neste artigo é de Attardo (2001). Foi ele o responsável por introduzir este conceito nos estudos de humor em seu livro Humorous texts: a semantic and pragmatic analysis. Para o autor, a definição e caracterização é complexa e, por isso, subdivide em outros cinco tópicos, a saber: narrativas estruturalmente similares a piadas; enredo metanarrativo; enredo com fabulae humorística; enredo com fabulae séria e, por fim, rompimento humorístico e ilusão realística.

Em "narrativas estruturalmente similares a piadas", o autor enfatiza a necessidade da punch line para finalizar o texto, pois é a presença dela que caracteriza um texto como uma piada ou similar à piada. Punch line, de acordo com Raskin (1985), é o elemento surpresa, "ela fornece uma mudança de um nível de abstração para outro, e a mudança ocorre "em um espaço de segundos"” (RASKIN, 1985, p. 33, tradução nossa). Pautado nos estudos semânticos de Raskin e os ampliando, Attardo (2001) entende a punch line a partir de uma perspectiva textual, concebendo-a como algo que atua como elemento de interrupção, que aciona um outro "script" incompatível com o cenário dado do texto, muda-se, portanto, a interpretação do que se lia.

No segundo tópico, "enredo metanarrativo", as convenções do modo narrativo são violadas com o propósito de humor, no ponto em que o desenvolvimento narrativo (trama/fabula) é monopolizado pelo objetivo humorístico do texto" (ATTARDO, 2001, p. 94; tradução nossa). O terceiro tópico, enredo com "fabulae humorística", é para o autor uma classe de textos que não terminam necessariamente com a punch line, mas que podem ser considerados uma história humorística. Já no tópico seguinte, o autor trata de fabulae sérias, que podem conter uma narrativa humorística, mas que essa é sobreposta pela seriedade da narrativa, dando como exemplo o romance de Umberto Eco, O Nome da Rosa. O último tópico, "rompimento humorístico e ilusão realística", trata de narrativas sérias, mas que nelas contém uma quebra para uma passagem humorística, mas que não chega a ser engraçada, pois não há elemento surpresa.

Acreditamos, assim como Attardo (2001) expôs, ser um conceito complexo e que ainda necessita ser melhor descrito e analisado em narrativas de humor mais extensas que as piadas. Por ser, então, o enredo humorístico um recurso promissor para a produção de sentido humorístico, que percebemos ser útil às análises associar a presença não só de punch line, como já indicado acima, mas também, e principalmente, de jab line à composição do enredo humorístico. A jab line "[...] indica a ocorrência de uma instância humorística em qualquer lugar que ocorra[...]" (ATTARDO, 2008, p. 110; tradução nossa), pois elas não só estão integradas à narrativa, com também contribuem para o desenvolvimento da mesma. Além disso, segundo Archakis e Tsakona (2005, p. 45; tradução nossa), "a jab line é uma palavra, uma frase ou uma sentença que inclua uma oposição de script". Logo, a ocorrência de jab line, nas referidas condições, sinalizaria a presença de enredo humorístico.

Útil também à composição de um enredo humorístico é o significativo estudo de Raskin (1985) sobre a teoria semântica do humor, por ele ter sido um dos primeiros a verificar a oposição de scripts em piadas. Segundo Raskin (1985), uma piada se caracteriza como tal se "o texto é compatível, em um todo ou em parte, com dois scripts diferentes" e se "os 
dois scripts com que o texto é compatível são opostos em um sentido especial [...]" (RASKIN, 1985, p. 99; tradução nossa, grifos do autor).

Além disso, é necessário ressaltar que para Raskin (1985) a piada é constituída de um sentido confiável (bona-fide) e outro não confiável (non-bona-fide), o que resulta na incongruência do texto, na oposição de scripts. Dada a substancial contribuição do estudo de Raskin (1985) para se compreender e se analisar a constituição do humor, julgamos ser significativa a verificação de oposição de scripts e de sentido bona-fide e non-bonafide na produção de um enredo humorístico, mesmo não sendo uma piada.

A partir do exposto, analisamos, a seguir, os textos que compõem o nosso corpus a fim compreender a produção de humor por meio da existência de enredo humorístico.

\section{NOTÍCIAS HUMORÍSTICAS. HUMORÍSTICAS POR QUÊ?}

Estamos classificando os textos como humorísticos por termos notado a presença de recursos de produção do humor, a saber: enredo humorístico constituído de jab line, de sentido bona-fide e non-bona-fide, de oposição de scripts e da punch line. Não consideramos que os textos coletados sejam piadas, já que são narrativas mais longas, como se vê em (1), (2) e (4) e porque se aproximam da estrutura do gênero notícia, como já verificado. Analisemos mais um exemplo, este do site G17:

\section{(5) Músicas dos cantores baianos não ficarão prontas para a Copa do Mundo}

Em função da preguiça, que ronda todo o estado da Bahia, as músicas dos baianos talvez não fiquem prontas a tempo de serem tocadas durante a Copa do Mundo, causando mais uma preocupação para o governo.

Como se não bastasse a falta da infraestrutura de estádios, rodovias, aeroportos e hotéis, agora corre se o risco de faltar também as músicas.

A presidente do país rico e sem pobreza, Dilma Rousseff, determinou o investimento, através do Ministério da Cultura, de 3 bilhões de reais, para agilizar a composição de hits para a Copa do Mundo.

A maior disputa pela música da Copa se concentra entre a loira e a morena: Claudia Leitte vs Ivete Sangalo. No entanto, outros grupos musicais, como o Bonde das Maravilhas também se beneficiarão com recursos do governo. A proposta do ministério da cultura é de fazer o Bonde das Maravilhas criar hits para a Copa do Mundo, especialmente para atender a uma parcela de pessoas, que adoram viver do Bolsa Família.

A notícia humorística (5) utilizou-se da informação mais noticiada antes do início da Copa: o atraso na entrega das obras; além do estereótipo existente para o povo baiano, o de preguiçosos, e das possíveis desavenças entre as cantoras Claudia Leite e Ivete Sangalo para construir o enredo humorístico. Esses fatos presentes no texto sob análise constituem o sentido bona-fide. Por outro lado, dizer que as músicas não ficariam prontas para a Copa 
seria o sentido non-bona-fide e a ele também faz parte o valor de 3 bilhões investidos por meio do Ministério da Cultura. Já no que tangem as oposições de scripts existentes no texto (5) temos: PREGUIÇA vs EFICIÊNCIA e COPA DO MUNDO vs PESSOAS DE BAIXA RENDA.

Com base na teoria desenvolvido por Attardo (2001), verificamos um enredo com história humorística, pois a complicação central envolve uma oposição de scripts humorísticos, elencados no parágrafo anterior. Não se esperava na época que as músicas não ficassem prontas nem mesmo que o Ministério da Cultura investisse em funk para agradar aos beneficiários do bolsa família, ou seja, essas são passagens que funcionam como gatilhos para deflagração do humor.

Ademais, deve-se, ainda, levar em consideração a presença das seguintes jab lines: "em função da preguiça, que ronda todo o estado da Bahia"; "agora corre se o risco de faltar também as músicas"; "país rico e sem pobreza". Por fim, apesar de ela não ser necessária em um enredo com história humorística (ATTARDO, 2001), a punch line se faz presente no texto (5), sendo ela: "atender a uma parcela de pessoas, que adoram viver do Bolsa Família".

Analisemos agora a construção do humor na notícia (6) do site O Bairrista.

\begin{tabular}{|l}
$\begin{array}{l}\text { (6) Quinta, } 10 \text { de Julho de } 2014 \\
\text { Felipão lamenta não ter jogado em Porto Alegre durante a } \\
\text { Copa }\end{array}$ \\
Três semifinalistas passaram pela capital. Dois deles estão na final. \\
O vexame histórico que o Brazil proporcionou aos brazileirinhos nunca \\
será esquecido. Os 7 a 1 sofridos contra a Alemanha entraram para os \\
anais da história do futebol como a maior derrota da seleção canário em \\
todos os tempos. Uma derrota difícil de ser esquecida e que gerou uma \\
série de questionamentos: mudança no calendário? Profissionalização e \\
modernização da CBF? Nossos técnicos estão desatualizados? Nada \\
disso. Essa é a opinião do técnico Felipão. \\
- Nosso erro foi não ter jogado em Porto Alegre. Somos a única seleção \\
que não jogou na capital Gaúcha. Essa estatística pesou contra nós - \\
disse o técnico na coletiva concedida na tarde desta quarta (9). \\
Ainda recolhendo os cacos de uma seleção que foi patrolada por uma \\
Alemanha que não se via tão destruidora desde a segunda guerra, \\
Felipão reconhece que chegou longe demais por não ter jogado na \\
Capital. \\
- Nós fomos até a semi sem ter passado perto do Rio Grande do Sul. É \\
um grande feito - disse Scolari.
\end{tabular}

No enredo humorístico do exemplo (6) há como sentido bona-fide as três seleções que jogaram em Porto Alegre: Holanda, Argentina e França e o placar do jogo entre Brasil e Alemanha. Mas relatar que o técnico Felipão lamentou não ter jogado na capital representa o sentido non-bona-fide. Além disso, como sentido non-bona-fide temos também a distorção dos fatos, pois as três seleções citadas não jogaram as semifinais, mas sim as quartas de final e duas dessas três seleções não foram para a final, só a Argentina 
foi finalista. Disso ocorre a oposição de scripts: DERROTA vs VITÓRIA. Há ainda a presença de jab lines, são elas: "Brazill"; "brasileirinhos"; "entraram para os anais da história do futebol"; "recolhendo os cacos de uma seleção que foi patrolada por uma Alemanha que não se via tão destruidora desde a segunda guerra". Nesta notícia humorística não há a presença da punch line, e de acordo com a definição de fabulae humorística, não há a necessidade de se encerrar com punch line.

Com base nos dados apresentados, traçamos o seguinte perfil para o corpus coletado: todos os textos basearam-se, para o sentido bona-fide, em acontecimentos reais comprováveis por meio de buscas e verificação nos portais de notícia com maior credibilidade. Além disso, diante dos resultados das análises, é mais comum, nas notícias humorísticas, a presença de duas oposições de scripts e não só de uma como prevê Raskin (1985) para a produção de piadas. É característica desse gênero, ainda, a presença do recurso de jab lines, caracterizando a ocorrência de enredo humorístico. Por fim, uma característica que não era prevista para as notícias humorísticas, mas se fez presente foi a existência de punch line, um elemento próprio e obrigatório das piadas que esteve presente na produção do enredo humorístico do nosso corpus.

\section{ALGUMAS CONSIDERAÇÕES FINAIS}

A Internet modificou bastante a vida das pessoas, seja no que diz respeito à vida social, ao mercado de trabalho, ao acesso à informação, ao aprendizado, à privacidade, à segurança e, principalmente, na forma de interação entre elas. Graças a Internet, comunicamo-nos facilmente com quem está distante, via e-mail, Skype, WhatsApp e redes sociais. Dada a facilidade de se ter acesso em tempo real ao que acontece pelo mundo, um gênero híbrido surgiu, as notícias humorísticas.

Após a análise das notícias humorísticas, podemos afirmar que elas constituem um gênero discursivo, híbrido, pois simula a prática social do jornalismo, mas pertence à prática social do humor, por terem como propósito comunicativo o entretenimento além da crítica social.

Por último, no que diz respeito à produção de sentido humorístico, verificamos que as notícias humorísticas dos sites analisados (Sensacionalista, G17 e O Bairrista), podem ser sim classificadas como cômicas, pois são constituídas de enredo humorístico, mais especificamente, enredo com fabulae humorística, ressaltando que, para isso, foi necessário o autor dos textos fazer uso dos recursos: sentido bona-fide e sentido nonbona-fide, oposição de scripts, presença de jab e punch lines.

\section{REFERÊNCIAS}

ARCHAKIS, Argiris; TSAKONA, Villy. Analyzing conversational data in GTVH terms: a new approach to the issue of identity construction via humor. Humor, 18-1, 41-68, 2005.

ATTARDO, S. A primer for the linguistics of humor. In: RASKIN, V. The primer of humor research. Mouton de Gruyter: Berlin; New York, 2008.

ATTARDO, Salvatore. Humorous Texts: a semantic and pragmatic analysis. Mouton de Gruyter: Berlin; New York, 2001. 
DAMÉ, L. Papa manda mensagem aos brasileiros para a Copa e pede solidariedade e paz. O GLOBO. Disponível em https://oglobo.globo.com/esportes/copa-2014/papa-manda-mensagemaos-brasileiros-para-copa-pede-solidariedade-paz-12818917. Acessado em 10 maio 2018.

FAIRCLOUGH, N. Critical Discourse Analysis: the Critical Study of Language. Longman: London, 1995.

FAIRCLOUGH, N. Analysing discourse: textual analysis for social research. Routledge: London, 2003.

FAIRCLOUGH, N. Discurso e mudança social. Trad. Bras. Brasília: Ed. da UnB, 2001[1992]. FAIRCLOUGH, N. Language and power. Longman: New York, 1989.

CHOULIARAKI, L.; FAIRCLOUGH, N. Discourse in Late Modernity. Edinburgh: Edinburgh University Press, 1999.

FREITAS, D.A.S. et. al. Textos eletrônicos: novos gêneros textuais? Humanidades, v. 3, n. 1, fev. 2014.

G17. Novo Papa faz oração para pedir a vitória da Argentina na Copa do Mundo no Brasil. Disponível em http://www.g17.com.br/noticia/mundo/novo-papa-faz-oracao-para-pedir-avitoria-da-argentina-na-copa-do-mundo-no-brasil.html. Acessado em 10 maio de 2018.

G17. Músicas dos cantores baianos não ficarão prontas para a Copa do Mundo. Disponível em http://www.g17.com.br/noticia/copa2014/musicas-dos-cantores-baianos-nao-ficarao-prontaspara-a-copa-do-mundo.html?fb_comment_id=178916455606674_475035\#f31d9866b23ca35c. Acessado em 10 maio de 2018.

O BAIRRISTA. RS desiste de sediar Copa de 2014 junto com o Brazil. Disponível em http://obairrista.com/esportes/2011/10/rs-desiste-de-sediar-copa-de-2014-junto-com-o-brazil/.

Acessado em 10 maio 2018.

O BAIRRISTA. Felipão lamenta não ter jogado em Porto Alegre durante a Copa. Disponível em http://obairrista.com/esportes/2014/07/felipao-lamenta-nao-ter-jogado-em-porto-alegre-durantea-copa. Acessado em 10 maio 2018.

POSSENTI, Sírio. Humor, língua e discurso. São Paulo: Contexto, 2010.

RASKIN, Victor. Semantic Mechanisms of Humor. Dordrecht: D. Reidel. 1985

SENSACIONALISTA. Dilma revela: Mick Jagger é o responsável pelos gastos da Copa. Disponível em https://www.sensacionalista.com.br/2014/06/03/dilma-revela-mick-jagger-e-oresponsavel-pelos-gastos-da-copa/. Acessado em 10 maio 2018.

SENSACIONALISTA. Saci Pererê vai dar o pontapé inicial da Copa no Brasil. Disponível em https://www.sensacionalista.com.br/2014/06/12/saci-perere-vai-dar-o-pontape-inicial-da-copano-brasil/. Acessado em 10 maio 2018.

SILVEIRA, Karine. Desnotícias sobre o Acre: a construção do humor e de identidades sociais. Dissertação. Mestrado em Linguística. Universidade Federal do Espírito Santo, Vitória, ES, 2013.

Artigo recebido em: ago. de 2018.

Aprovado e revisado em: nov. de 2018.

Publicado em: dezembro de 2019.

Para citar este texto:

SILVEIRA, Karine. A internet como ambiente propício para o surgimento de gêneros híbridos: em foco as notícias humorísticas. Entremeios [Revista de Estudos do Discurso, ISSN 2179-3514, on-line, www.entremeios.inf.br], Seção Estudos, Programa de Pós-Graduação em Ciências da Linguagem (PPGCL), Universidade do Vale do Sapucaí (UNIVÁS), Pouso Alegre (MG), vol. 18, p. 93-106, jan. - jun. 2019.

DOI: http://dx.doi.org/10.20337/ISSN2179-3514revistaENTREMEIOSvol18pagina93a106 